stenosis. Original Article. 2014; 12(2):30-32.

7. Ta Quốc Huân và Nguyê̂n Thì Bach Yến. Mối liển quan giữa dấu hiêu $\mathrm{T}$ âm ở chuyển đao $\mathrm{aVL}$ trên điện tâm đồ với tổn thương động mạch liên thất trước trên hình ảnh chup động mach vành qua da ở bệnh nhân bệnh động mạch vành ổn định. Luận văn Thạc sỹ y học , Đại học Y Hà Nội. 2019;
8. Kracoff OH, Adelman AG, Marquis JF, Caspi A, Aldridge HE, Schwartz L. Twelve-lead electrocardiogram recording during percutaneous transluminal coronary angioplasty. Analysis of reciprocal changes. Journal of electrocardiology. $1990 ; 23(3): 191-8$.

\title{
ĐĂC ĐIỂM LÂM SÀNG VÀ CÂN LÂM SÀNG CỦA BỆNH NHÂN NGộ ĐộC CẤP MộT SỐ THUỔC AN THẦN KINH THƯỜNG GẶP
}

\section{TÓM TẮT}

Mục tiêu: Mô tả đặc điểm lâm sàng và cân lâm sàng của bệnh nhân ngộ độc cấp một số thuốc an thần kinh (ATK) thường gặp tại Trung tâm Chống độc Bệnh viện Bạch Mai. Phương pháp: Nghiên cứu mô tả tiến cứu trên 61 bệnh nhân ngộ độc cấp thuốc an thần kinh tại Trung tâm chống độc, Bênh viên Bach Mai từ tháng 1 năm 2020 tới tháng 6 năm 2021. Kết quả: Trong số bệnh nhân nghiên cứu, nữ chiếm $55,7 \%$, tuổi trung bình là 38,9 $\pm 18,6$ (15 - 81), nguyên nhân ngộ độc hay gặp nhất là tự tử $(88,5 \%)$. 68,8\% bệnh nhân ngộ độc nhóm ATK không điển hình nhiều hớn so với ngổ độc nhóm thuốc ATK điển hình (26,2\%). Đa số bệnh nhân nhập viện với triệu chứng nhe, trung bình $77,1 \%$, các triệu chứng lầm sàng thường gặp gồm giám ý thức $(37,7 \%)$, mạch nhanh $(42,6 \%)$, suy hô hấp $(23 \%)$ và đồng tứ co $(16,4 \%)$. Thay đổi điện tim hay gặp gồm nhịp nhanh xoang và QT kéo dài. Kết luân: nghiên cứu đã cho thấy các đặc điểm lâm sàng và cận lâm sàng chính của bệnh nhân ngộ độc cấp một số thuốc an thần kinh thường gặp.

Tư khóa: thuốc an thần kinh, ngộ độc cấp, đặc điểm lâm sàng và cận lâm sàng

\section{SUMMARY \\ CLINICAL FEATURES AND LABORATORY ABNORMALITIES OF SOME COMMON NEUROLEPTIC POISONINGS}

Objectives: to describe the clinical characteristics and laboratory features of patients with acute poisoning of some common neuroleptics at Vietnam Poison Control Center, Bach Mai Hospital. Methods: A prospective observational study included 61 patients poisoned by some common neuroleptics from January 2020 to October 2021. Results: Among the study patients, female accounted for $55.7 \%$, the mean age was $38.9 \pm 18.6(15-81)$ years old, the most common cause of poisoning was suicide ( $88.5 \%) .68 .8 \%$ of the patients were poisoned with atypical neuroleptics,

\footnotetext{
${ }^{1}$ Trường Đại học Y Hà Nội,

${ }^{2}$ Trung tâm Chống độc

Chịu trách nhiệm chính: Lưu Văn Hậu

Email: luuvanhau211@gmail.com

Ngày nhận bài: 18.8.2021

Ngày phản biên khoa hoc: 14.10.2021

Ngày duyệt bài: 21.10.2021
}

\section{Lưu Văn Hậu ${ }^{1}$, Đặng Thị Xuân²}

more common than typical group (26.2\%). Most of the patients were hospitalized with mild symptoms (77.1\%), common clinical symptoms include unconsciousness (37.7\%), tachycardia (42.6\%), respiratory failure (23). \%) and pupil constriction (16.4\%). Common electrocardiographic changes included sinus tachycardia and QTC prolongation. Conclusion: The study revealed the main clinical and laboratory characteristics of patients with acute poisoning of some common neuroleptics.

Keywords: neuroleptics, acute poisoning, clinical and laboratory characteristics

\section{I. ĐĂT VẤN ĐỀ}

Thuốc an thần kinh (ATK) hay thuốc chống loạn thân là nhóm thuốc được sử dụng rộng rãi trong điêu trị các rối loạn tâm thân bao gồm tâm thân phân liệt (TTPL), rối loạn cảm xúc lưỡng cực, các rối loạn trâm cảm nặng... Những năm trở lại đây, việc sử dụng thuốc ATK trong điều trị các bênh lý không do nguyên nhân tâm thân đang ngày càng gia tăng, bao gồm điều trị tình trạng nôn không đáp ứng với điều trị chống nôn thông thường, đau đâu, chóng mặt, hội chứng Tourette, và đau thân kinh liên sườn...1. Các thuốc ATK được chia thành hai nhóm: điển hình và không điển hình. Nhóm ATK điển hình bao gồm các thuốc như butyrophenon, dibenzoxapin, diphenylbutylpiperidin và phenothiazin. Nhóm không điển hình bao gồm các thuốc mới như bezopin, indol, quinolinon².

Ngộ độc thuốc ATK được chẩn đoán dựa vào tiên sử sử dụng thuốc, các hội chứng và triệu chứng lâm sàng bao gồm: giảm ý thức, hội chứng kháng cholinergic, hội chứng ngoại tháp, các triệu chứng trên hệ tim mạch, co giật vv. Bệnh nhân (BN) ngộ độc thuốc ATK nặng có thể hổn mê, tụt huyết áp, hội chứng QT kéo dài, xoắn đỉnh thậm chí rung thất, tử vong. Xét nghiệm đo nồng độ thuốc ATK trong huyết thanh không được sư dụng rộng rãi và không hữu ích trong điêu trị ngộ độc ATK, do đó việc khám lâm sàng đây đủ, chính xác đóng vai trò quan trọng 
giúp chẩn đoán đúng, xử trí kịp thời, hạn chế các biến chứng ${ }^{3}$. Ngộ độc thuốc cấp thuốc ATK thường gặp, mỗi nhóm thuốc lại gây ra các biến chứng về thần kinh, tim mạch, mức độ nặng cũng như nguy cơ tử vong khác nhau. Hiện nay, ngày càng có thêm nhiều nhóm thuốc ATK mới đang được sử dụng, tuy nhiên chưa có nghiên cứu nào đánh giá một cách tổng thể về ngộ độc cấp các thuốc ATK. Do đó chúng tôi tiến hành nghiên cứu với mục tiêu mô tả đặc điểm lâm sang và cận lâm sàng của bệnh nhân ngộ độc cấp một số thuốc an thân kinh thường gặp tại Trung tâm Chống độc Bệnh viện Bạch Mai.

\section{II. ĐỐI TƯỢNG VÀ PHƯƠNG PHÁP NGHIÊN CỨU}

2.1. Đổi tượng nghiên cứu: Các bệnh nhân được chẩn đoán ngộ độc cấp thuốc an thần kinh nhậ̣p viện điều trị tại trung tâm chống độc bệnh viện Bạch mai từ 1/2020 đến tháng 06/2021.

Tiêu chuẩn chọn bệnh nhân: Bệnh nhân có đủ $2 / 3$ tiêu chuẩn sau:

- Bệnh nhân có dùng thuốc an thần kinh

- Có triệu chứng lâm sàng của ngộ độc thuốc an thần kinh

- Xét nghiệm độc chất dương tính

Tiêu chuẩn loại trừ: Bệnh nhân ngộ độc đồng thời thuốc và hóa chất khác, bệnh nhân có bệnh lý thần kinh.

\subsection{Phương pháp nghiên cứu}

Nghiên cứu mố tả tiến cứu

Cách chọn mẫu nghiên cứu: chọn tất cả các đối tượng thỏa mãn tiêu chuẩn chọn trong thời gian nghiên cứu

\subsection{Nội dung nghiên cứu}

Đặc điểm chung của nhóm nghiên cứu. Phân bố tuổi, giới, nghề nghiệp, tiền sử bệnh, nguyên nhân ngộ độc, thời gian từ lúc uống/tiêm đến lúc nhập viện, thời gian nằm viện.

Đặc điểm lâm sang của bệnh nhân ngộ độc cấp thuốc an thân kinh thường gặp

Nhịp tim, huyết áp, thân nhiệt, nhịp thở, $\mathrm{SpO}_{2}$

Triệu chứng các cơ quan:

Thẩn kinh: Rối loạn ý thức (Glasgow), đồng tử, phản xạ gân xương, trương lực cớ, rối loạn vận động

Tim mạch: đau ngực, hồi hộp, đánh trống ngực, ngất. Nhịp tim nhanh, nhịp tim chậm, rối loạn nhịp

Hô hấp: Suy hô hấp, đặt nội khí quản, thở máy

Tiêu hóa: Buồn nôn, nôn, chướng bụng, giảm nhu động ruột

Các hội chứng ngộ độc: Hội chứng serotonin, hội chứng kháng cholinergic, hội chứng ngoại tháp, hội chứng an thần kinh ác tính.

Đặc điểm cận lâm sàng:
+ Độc chất: xét nghiệm định tính thuốc an thần kinh trong nước tiểu

+ Điện tâm đồ: tần số, nhịp, thời gian QRS, thời gian Qt

+ Tổng phân tích tế bào máu ngoại vi: số lượng hồng cầu, bạch cầu, tiểu cầu

+ Sinh hóa máu: ure, creatinin, glucose, điện giải đồ, GOT, GPT, CK

+ Khí máu: $\mathrm{pH}, \mathrm{PaCO}_{2}, \mathrm{PaO}_{2}, \mathrm{HCO}_{3}{ }^{-}$,lactat

+ Các xét nghiệm thăm dò khác giúp chẩn đoán: $X$ quang tim phổi, CLVT sọ não, siêu âm ổ bụng

+ Đánh giá mức độ nặng khi nhập viện PSS

2.4. Phương pháp xử lý số liệu. Các số liệu được phân tích theo phương pháp thống kê y học, sử dụng phần mềm SPSS 20. Tính tỉ lệ phần trăm cho các biến định tính, các biến định lượng biểu thị bằng giá trị trung bình, độ lệch chuẩn hoặc trungvị, giá trị nhỏ nhất, lớn nhất, so sánh trung bình bằng $\mathrm{t}$ test, so sánh tỷ lệ \%bằng $X^{2}$ (hoặc Fisher exact test).

\section{KẾT QUẢ NGHIÊN CỨU}

Trong 61 bệnh nhân ngộ độc cấp thuốc an thần kinh đủ tiêu chuẩn tham gia vào nghiên cứu, có 34 BN nữ $(55,7 \%)$, tỷ lệ nữ/nam là $1,3 / 1$, tuổi trung bình là $38,9 \pm 18,6$ (nhỏ nhất: 15 , cao nhất: 81$)$, nhóm tuổi 18-29 gặp nhiều nhất $(36,1 \%)$, sau đó là nhóm $30-39(24,6 \%)$ và trên 59 tuổi (23\%).

\section{1. Đặc điểm lâm sàng Nguyên nhân ngộ độc}

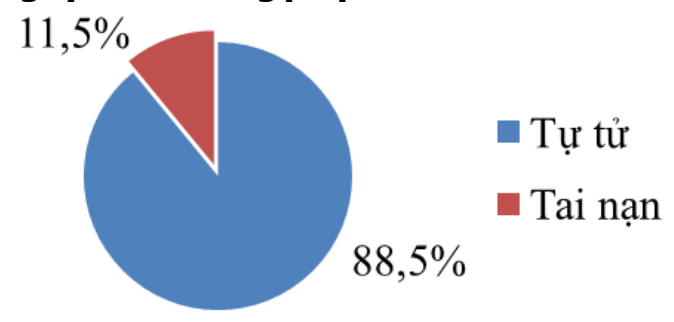

Biều đồ 1. Nguyên nhân ngộ độc

Nhận xét: Nguyên nhân ngộ độc hay gặp nhất là tự tử $54 \mathrm{BN}(88,5 \%)$, do tai nạn $7 \mathrm{BN}$ (11,5\%) đa số do bệnh nhân già, uống nhầm thuốc.

Loại thuốc gây ngộ độc

Bảng 1. Loại thuốc gẩy ngộ độc

\begin{tabular}{|c|c|c|c|}
\hline $\begin{array}{c}\text { Nhóm } \\
\text { thuốc }\end{array}$ & Loại thuốc & $\begin{array}{c}\text { Số lượng } \\
(\mathbf{n})\end{array}$ & $\begin{array}{c}\text { Tỷ lệ } \\
(\mathbf{\%})\end{array}$ \\
\hline \multirow{3}{*}{$\begin{array}{c}\text { An thần } \\
\text { kinh điển } \\
\text { hình }\end{array}$} & Levomepromazin & 7 & 11.5 \\
\cline { 2 - 4 } & Chlopromazin & 5 & 8,2 \\
\cline { 2 - 4 } & Haloperidol & 4 & 6,6 \\
\cline { 2 - 4 } & Tổng & 16 & 26,2 \\
\hline & Olanzapin & 15 & 24,6 \\
\cline { 2 - 4 } & Quetiapin & 12 & 19,7 \\
\hline
\end{tabular}




\begin{tabular}{|c|c|c|c|}
\hline \multirow{4}{*}{\begin{tabular}{|c|} 
An thân \\
kinh không \\
điển hình
\end{tabular}} & Clozapin & 9 & 14,8 \\
\hline & Risperidol & 6 & 9,8 \\
\hline & Amisulpirid & 3 & 4,9 \\
\hline & Tổng & 42 & 68,8 \\
\hline & & 61 & 100 \\
\hline
\end{tabular}

Nhân xét: Có 42 BN $(68,8 \%)$ ngộ độc nhóm thuốc ATK không điển hình nhiều hơn so với 16 BN $(26,2 \%)$ ngộ độc nhóm thuốc ATK điển hình. Loại thuốc gây ngộ độc hay gặp nhất là Olanzapin 15 BN $(24,6 \%)$ và Quetiapin $12 \mathrm{BN}$ $(19,7 \%)$, tiếp đến là Clozapin với 9 BN $(14,8 \%)$, Levomepromazin với 7 BN $(11,5 \%)$.

Thời gian từ lúc uống đến lúc nhập viện

Nhânn xét: Thời gian từ khi ngộ độc đến khi nhập viện dưới 6 giờ chiếm tỷ lệ cao nhất với 36 $\mathrm{BN}(59,0 \%)$, tiếp theo là nhóm 6-12 giờ với 13
BN $(21,3 \%)$, nhóm trên 12 giờ gặp ít nhất với 12 BN (19,7\%).

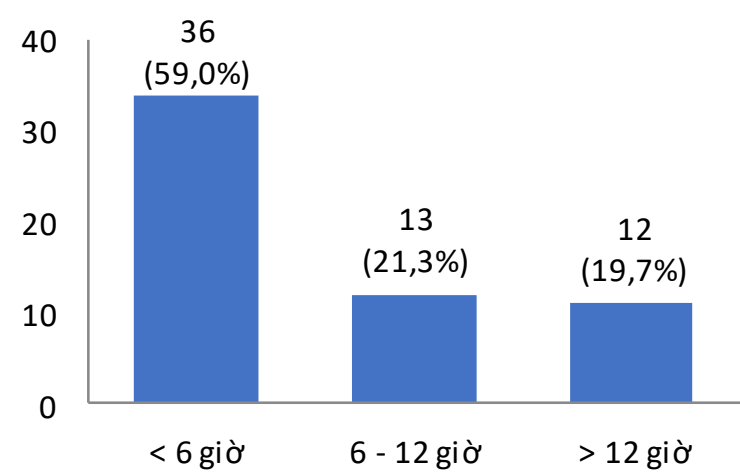

Biều đồ 2. Thời gian từ lúc uống đến lúc nhập viện

Phân loại triệu chứng lâm sàng theo nhóm thuốc

Bảng 2. Phân loại triệu chứng lâm sàng theo nhóm thuốc

\begin{tabular}{|c|c|c|c|c|c|c|c|}
\hline & \multicolumn{2}{|c|}{$\begin{array}{c}\text { Điến hình } \\
\text { (n=16) }\end{array}$} & \multicolumn{2}{c|}{$\begin{array}{c}\text { Không điển hình } \\
\text { (n=45) }\end{array}$} & \multicolumn{2}{|c|}{ Tổng } & \multirow{2}{*}{$\mathbf{p}$} \\
\cline { 2 - 7 } & $\mathbf{n}$ & $\mathbf{\%}$ & $\mathbf{n}$ & $\mathbf{\%}$ & $\mathbf{n}$ & $\mathbf{\%}$ & \\
\hline Giảm ý thức & 8 & 50 & 15 & 33,3 & 23 & 37,7 & 0,237 \\
\hline Mạch nhanh & 9 & 56,3 & 17 & 37,8 & 26 & 42,6 & 0,199 \\
\hline Tăng huyết áp & 2 & 12,5 & 3 & 6,7 & 5 & 8,2 & 0,599 \\
\hline Tụt huyết áp & 0 & 0 & 2 & 4,4 & 2 & 3,3 & 1,0 \\
\hline Suy hốn hấp & 4 & 25 & 10 & 22,2 & 14 & 23 & 1,0 \\
\hline Buônn nôn, nôn & 0 & 0 & 3 & 6,7 & 3 & 4,9 & 0,56 \\
\hline HC kháng cholinergic & 0 & 0 & 6 & 13,3 & 6 & 9,8 & 1,0 \\
\hline HC serotonin & 0 & 0 & 1 & 2,2 & 1 & 1,6 & 0,459 \\
\hline HC ngoại tháp & 1 & 6,3 & 1 & 2,2 & 2 & 3,3 & 1,0 \\
\hline
\end{tabular}

Nhận xét: Triệu chứng giảm ý thức, mạch nhanh, suy hô hấp gặp ở nhóm ATK điển hình nhiều hơn nhóm ATK không điển hình, tuy nhiên chưa thấy khác biệt có ý nghĩa thống kê. Hội chứng serotonin chỉ găp ở nhóm ATK không điển hình với 1 BN $(2,2 \%)$ ngộ độc Quetiapin. Tương tứ, chî gặp hội chứng kháng Cholinergic ở nhóm ATK không điển hình với 6 BN $(13,3 \%)$ bao gồm 3 BN ngộ độc Olanzapin, 1 BN ngộ độc Risperidol, 1 BN ngộ độc Clozapin

\section{2. Đặc điểm cân lâm sàng}

\section{Bảng 3. Đăc điểm về điện tim}

\begin{tabular}{|c|c|c|c|c|c|c|}
\hline & \multicolumn{2}{|c|}{ Chung } & \multicolumn{2}{c|}{ ATK điển hình (n=13) } & \multicolumn{2}{c|}{ ATK không điển hinh (n=41) } \\
\cline { 2 - 7 } & $\mathbf{n}$ & $\mathbf{\%}$ & $\mathbf{n}$ & $\mathbf{\%}$ & $\mathbf{n}$ & $\mathbf{\%}$ \\
\hline Bình thường & 41 & 70,7 & 9 & 69,2 & 31 & 75,6 \\
\hline Nhịp chậm xoang & 1 & 1,7 & 0 & 0 & 1 & 2,4 \\
\hline Nhịp nhanh xoang & 16 & 27,6 & 4 & 30,8 & 9 & 22,0 \\
\hline Biến đổi ST-T & 3 & 5,2 & 1 & 7,7 & 2 & 48,8 \\
\hline QTc kéo dài & 9 & 15 & 3 & 23,1 & 6 & 14,6 \\
\hline
\end{tabular}

Nhận xét: Rối loạn điện tim thường găăp nhất trong ngộ độc thuốc an thần kinh là rối loạn nhịp nhanh với 16 BN $(27,6 \%)$, 3 BN $(5,2 \%)$ có biến đổi đoan ST-T, 9 BN (15\%) có Qt kéo dài. QTc kéo dài gặp ở 3 BN $(23,1 \%)$ nhóm ngộ độc thuốc ATK điển hình, 6BN (14,6\%) ngộ độc thuốc ATK không điển hình.

Bảng 4. Đặc điểm về toan kiềm

\begin{tabular}{|c|c|c|c|c|}
\hline & ATK điến hình & ATK không điến hình & Chung & p \\
\hline Toan hô hấp & 0 & $2(5,6 \%)$ & $2(3,9 \%)$ & $>0,05$ \\
\hline Toan chuyến hóa & $1(6,7 \%)$ & $1(2,7 \%)$ & $2(3,9 \%)$ & $>0,05$ \\
\hline
\end{tabular}




\begin{tabular}{|c|c|c|c|c|}
\hline Kiềm hô hấp & $1(6,7 \%)$ & $5(13,9 \%)$ & $6(11,8 \%)$ & $>0,05$ \\
\hline Kiềm chuyển hóa & 0 & $5(13,9 \%)$ & $5(9,8 \%)$ & $>0,05$ \\
\hline Bình thường & $11(73,3 \%)$ & $25(69,4 \%)$ & $36(70,6 \%)$ & $>0,05$ \\
\hline Tổng & $\mathbf{1 5}$ & $\mathbf{3 6}$ & $\mathbf{5 1}$ & \\
\hline
\end{tabular}

Nhân xét: 36 BN (70,6\%) có khí máu bình thường, 6 BN (11,8\%) kiềm hô hấp. 5 BN (9,8\%) kiềm chuyển hóa. Có 2 BN có tình trạng toan chuyển hóa lúc nhập viện bao gồm 1 BN ngộ độc levomepromazin và $1 \mathrm{BN}$ ngộ độc Quetiapin. Có $2 \mathrm{BN}$ toan hô hấp lúc nhập viện và cả hai $\mathrm{BN}$ đều ngộ độc với Olanzapin.

\section{BÀN LUẬN}

Đặc điểm lâm sàng. Nguyên nhân ngộ hay gặp nhất trong nghiên cứu của chúng tôi là do tự tử $(88,5 \%)$, thấp hơn so với nghiên cứu của tác giả Arici MA với 95,5\% trường hợp ${ }^{4}$ do có một tỷ lệ bệnh nhân người già, ngộ độc do uống nhầm thuốc. Hầu hết bệnh nhân nhập viện trong vòng 6 giờ kể từ khi uống 59\%, thấp hớn nghiên cứu của Mubarak và cộng sự với $75 \%$ BN nhập viện trong vòng 5 giờ ${ }^{5}$. Điều này là do một số bệnh nhân được chuyển từ tuyến trước lên.

Trong nghiên cứu của chúng tôi, có $68,8 \%$ bệnh nhân ngộ độc nhóm thuốc ATK không điển hình, gặp nhiều hơn nhóm ATK điển hình $(26,2 \%)$, loại thuốc hay gặp ở nhóm ATK không điển hình là Quetiapin. Tương tự như nghiên cứu của Arici MA và cộng sự với $77 \%$ trường hợp nhập viện do ngộ độc ATK không điển hình và quetiapin là nguyên nhẩn gây ngộ độc thường gặp nhất ${ }^{4}$. Điêu này phản ánh sự gia tăng sử dụng các thuốc ATK không điển hình trong điều trị.

Trong nghiên cứu của chúng tôi, đa số BN nhập viện với triệu chứng nhẹ, trung bình $77,1 \%$, các triệu chứng lâm sàng thường gặp gồm giảm ý thức $37,7 \%$, mạch nhanh $42,6 \%$, suy hô hấp $23 \%$ và đồng tử co $16,4 \%$. Theo tác giả Mubarak và cộng sự khoảng một nửa các trường hợp nhập viện với các triệu chứng nhẹ như mạch nhanh $(46,67 \%)$, thở nhanh $(46,67 \%)$ và đồng tử co $(56,7 \%)$, trong khi chỉ có một tỷ lệ nhỏ bệnh nhân nhập viện trong tình trạng nặng như hồn mê Glasgow dưới 8 điểm $(8,3 \%)$ và rối loạn trương lực cơ $(6,7 \%)$.

Hội chứng kháng Cholinergic chỉ gặp ở nhóm ATK không điển hình chiếm 13,3\% bao gồm 3 BN ngộ độc Olanzapin, 1 BN ngộ độc Risperidol, 1 BN ngộ độc Clozapin. Hội chứng ngoại tháp gặp ở 3,3\%.

Đặc điểm cận lâm sàng. Rối loạn điện tim thường gặp nhất là nhịp nhanh xoang với $27,6 \%, 15 \%$ có QT kéo dài, $5,1 \%$ có biến đổi $\mathrm{ST}-\mathrm{T}$. Không có trường hợp nào xoắn đỉnh. Theo nghiên cứu của Tan $\mathrm{HH}$ và cộng sự, nhịp nhanh xoang và QTc kéo dài là những biến đổi điện tim thường gặp trong ngộ độc cấp thuốc chống loạn thần ${ }^{6}$. Theo Mubarak và cộng sự, nhịp nhanh xoang $(50 \%)$ và Qt kéo dài $(43 \%)$ là rối loạn điện tim hay gặp nhất trong ngộ độc thuốc an thần kinh.

$36 \mathrm{BN}(70,6 \%)$ có khí máu bình thường , 6 BN $(11,8 \%)$ kiềm hô hấp.5 BN $(9,8 \%)$ kiềm chuyển hóa tương tự với nghiên cứu của tác giả Mubarak với $66,7 \%$ BN có khí máu bình thường, 26,7\% BN kiềm hô hấp 5 .

\section{KẾT LUẬN}

Ngộ độc cấp thuốc an thần kinh thường gặp nhiều ở nhóm ATK không điển hình, đa số bệnh nhân nhập viện trước 6 giờ và nguyên nhân hay gặp gây ngộ độc là do tự tử. Triệu chứng lâm sàng thường gặp bao gồm mạch nhanh, giảm ý thức, suy hô hấp và đồng tử co. Thay đổi điện tim hay gặp gồm nhịp nhanh xoang và QT kéo dài.

\section{TÀI LIỆU THAM KHẢO}

1. Boushra $\mathbf{M}$, Nagalli $\mathbf{S}$. Neuroleptic Agent Toxicity. In: StatPearls. ; 2020.

2. DeSilva $P$, Fenton $M$, Rathbone J. Zotepine for schizophrenia. Cochrane Database Syst Rev. 2006; (4): CD001948. doi:10.1002/ 14651858.CD001948.pub2

3. Minns AB, Clark RF. Toxicology and overdose of atypical antipsychotics. J Emerg Med. 2012;43(5):906-913.

doi:10.1016/j.jemermed.2012.03.002

4. Journal of Basic and Clinical Health Sciences 》 Makale » Antipsychotic Exposures in an Emergency Department. Accessed October 31, 2021. https://dergipark.org.tr/tr/pub/jbachs/issue/58467/ 844615

5. Mubarak M, El Madah E, El Gharbawy D, Ashmawy M. Assessment of Acute Antipsychotic Poisoned Cases Admitted to Tanta University Poison Control Unit. Ain Shams Journal of Forensic Medicine and Clinical Toxicology. 2019;33(2):113125. doi:10.21608/ajfm.2019.43103

6. Tan HH, Hoppe J, Heard K. A systematic review of cardiovascular effects after atypical antipsychotic medication overdose. Am J Emerg Med. 2009; 27(5):607-616. doi:10.1016/ j.ajem.2008.04.020 